\title{
Health and Welfare: The Third Last Frontier of Microeconomic Reform
}

\author{
John Paterson
}

$\mathbf{M}$ icroeconomic reform of the Australian health and welfare system calls for the cleansing of intergovernmental arrangements. Pricing instruments can be used to replace 'command' arrangements if and only if catastrophic risk and income distribution issues are dealt with directly. Fiscal neutrality between existing funding sources (Commonwealth, State, and local government, and private payments) can be maintained while an efficient payment system is created. Agency arrangements can overcome market imperfections. User co-payment obligations should be enforced for all non-catastrophic health and welfare services. The 'gap' should be insurable but on a strictly commercial basis. Mandatory community rating can be abandoned if catastrophic risk is reinsured through the income tax system. Private health insurance is currently unsustainable but would then become viable. Improved organisation of primary care, reduced outlays on secondary and tertiary referral facilities and greatly improved levels of service would be the economic pay-off. Agency arrangements will decisively transfer control from provider to consumer - a major bonus.

\section{Why Health Is Not Different}

Microeconomic reform has rocked the corporate sector, reshaped primary industry, and stirred up government business enterprises. The Industrial Relations Club has demanded and received immunity. Teachers and academics also seem pretty safe: ALP branches are full of them. That leaves health and welfare as the only large chunk of the economy currently open to a national program of microeconomic reform. What would it mean?

The RAND Corporation demonstrated through massive experiments in the 1970s and 1980s that health care is amenable to conventional economic analysis: patient charges cut consumption; fee-for-service medicine increases consumption; other things equal, the rich consume more than the poor. These conclusions are reinforced by casual observation.

Health-care markets are imperfect, but what market is not? Health care contributes to long and healthy lives. So too does proper food, clothing, and exercise, which are usually treated as personal consumption choices. So why pretend that in

John Paterson is Secretary of the Victorian Department of Health \& Community Services. 
health care there is always a life at stake and invoke the full regulatory, organisational and financial might of the state as, at present, we do?

The utterly conventional and robustly stable economic character of health services is highlighted by the international consistency of the ratio of per capita spending on health to per capita GDP. Among the rich nations, international variations in health service consumption are 80-90 per cent associated with differences in real per capita income levels: that is, with an economic variable. The richer the country, the more spent, in relative terms, on health care. The residual variation in expenditure can be put down to politics.

Health care alone, even excluding welfare, is arguably the developed world's biggest industry; it typically accounts for 7-10 per cent of GDP. How strange it is that virtually every country has invented its own system, partly as a sentimental reflection of national traditions, and partly in the belief that health is 'different'. Most national motor vehicle industries used to possess distinctive ethnic characteristics. Then the Japanese came along and threatened to wipe them all out. Now they are all pretty much the same, and the Japanese are having a little trouble competing. Unfortunately, health and welfare services are not readily traded. If they were tradable, all rich countries would have something close to a world best-practice health industry. Instead, most have something as idiosyncratic as French agriculture, where one peasant can live well from running a herd of five cows, or to Japanese rice cultivation, where one farmer tends 2 ha of crop.

\section{Regulatory Losses}

The reasonable approach is to use market instruments where they can be used, and to separate 'life and death' elements of health and welfare for control by direct means. Our present elaborate regulatory system is premised on the opposite view; it tacitly assumes that every sniffle is life-threatening. We bear a heavy cost for this, through inefficiency in the bulk of health and welfare provisions that are not of a life-and-death character.

Of course, not all regulation is bad. Some regulations produce direct benefits that outweigh the systemic losses they cause. Most health-service consumers, for example, draw great comfort from the information that their practitioner is qualified and registered. They are willing to tolerate some reduction of competition in the interest of better information and assured minimum standards of competence. The aim must be to obtain that assurance as cheaply as possible. Providers can gain monopoly power by manipulating barriers to entry. If they are permitted to do so they corrupt the regulatory system by extending its application beyond the point where it serves only informational and quality assurance objectives. Losses then begin to outweigh the gains originally sought from the regulation.

There are many ways of corrupting a market. Australia's health and welfare system exhibits most of the recognised techniques for corrupting by regulation. Examples include:

- different pricing rules for close substitutes; 
- 'truck' systems that tie spending of 'company dollars' to purchases from the 'company store', through sharp demarcation of public and private provision and components thereof;

- legal differentiation by irrelevant attributes such as institutional history;

- monopolies, licences and patents that go beyond basic requirement for public information and quality assurance; and

- restrictions on trade across jurisdictional boundaries, whether geographic or administrative.

A multitude of overspecialised programs ties funds to providers. As a result, our national funding and providing system is like a giant egg crate. Governments place an eye-dropper full of dollars in each well; over-specialised niche providers drink from each well. A massive barrier exists between each well. This ensures that the integrated needs of the final consumer are impossible to meet unless a fortune is spent on 'coordination' to defeat the fundamental fragmentation of the system.

Each well is politicked over and administered. The different parties watch one another like hawks for signs of cost shifting and partiality between wells. At the same time, we all work away quietly doing a bit of cost shifting in our own favour if we can get away with it. The Commonwealth instinctively tries to play the States off against one another, partly for financial reasons, but substantially for hegemonic ones.

All this would be just fine if the sole objective was to keep politicians and officials entertained. Along the way, however, we all pretend that we want to provide some health and welfare services, at least as a by-product, of the real game. The long-suffering public remains deluded that their well-being is our concern.

If we were serious we would immediately play a different, and much simpler, game. Programs and jurisdictions would largely be abolished, entitlements would be attached to consumers, and providers would obtain business through a competitive market for the consumer dollar. There would be worthwhile reductions in bureaucratic overheads. The real gains, however, would accrue at the client/patient/customer interface, because the products of the system would change, and the biases introduced by differential financing and non-market allocation between similar services would be removed.

\section{Health Care Sans Doctrine}

Before seeking to unravel the present arrangements it is useful to understand their origins. A successful High Court challenge to Commonwealth pharmaceutical benefits arrangements in 1944 led to a constitutional amendment, which created new Commonwealth powers under section 51(23a) of the Constitution. These allowed the Commonwealth to make the laws that now underpin or buy in on an array of 'social' programs, including pharmaceutical, sickness, and hospital benefits, 
home care, emergency and supported accommodation, disability services, psychiatric services, the regulation of medical and dental services, and accreditation of childcare centres. The Commonwealth has made laws, raised taxes, paid out money. All parties have hired lots of officials to watch the officials of other governments, who in turn, watch them back.

Section 51(23a) was a charter for 'health services without doctrine'. It was not prescriptive about any hierarchical allocation of responsibility between Commonwealth, State and local governments, so no coherent hierarchy emerged. Everyone is in everything and no one is accountable. It never directly articulated roles for the public and private sectors respectively, in matters either of service provision or finance, so in effect we got two largely separate systems. Its inevitable result was a tangled web of intergovernmental arrangements marked by incomprehensible complexity. Its maintenance costs alone are enormous, because at the client interface there is not one service channel, but hundreds.

The recent precipitous decline in private health insurance is merely one small symptom of an out-of-joint system. Another is the emergence of a boarding-housedwelling underclass consequent upon de-institutionalisation of psychiatric services. You can defeat the logic of production systems with money for just so long. Then they break open, providing nasty surprises at every turn.

\section{Technology Hierarchy and Organisational Change}

The concurrent Commonwealth and State powers created by the Constitutional amendment meant that there was no single act of administrative design in Australia comparable to the Beveridge-inspired National Health Service in Britain. Each element of the system is defined more by its origins than by any serious consideration of its role in an integrated modern service system.

Australia's State hospital systems mostly had benevolent and charitable origins. The Commonwealth did not deal with the hospitals, apart from offering tax concession to their benefactors. The Commonwealth dealt with the States, which in turn licensed the lotteries, chocolate wheels, chook raffles and charity drives that paid for the ancestral public hospitals. The States, at the lower hierarchical level of government, retained the administrative control and held most of the property of the hospitals, the secondary/tertiary facilities sitting at the top of the health hierarchical system.

When Medibank was introduced the Commonwealth in effect took over the direct funding of primary medical care, the bottom of the treatment hierarchy. This is a paradox indeed: the central or hierarchically superior element of government financed and largely controlled the most 'local' or primary care elements of the health system. The State level of government retained the secondary and tertiary level facilities: an inversion of the normal hierarchical assignment.

Technological advances have progressively shifted the boundaries between hospital in-patient, day-procedure, and outpatient services, relative to GP services, community-health services, maternal and child health programs, school medical and dental programs and domiciliary support services. These boundaries will continue 
to change. Defence against cost shifting inhibits the adaptation of the services to changing technology.

People 65 years and over account for between 40-50 per cent of acute hospital bed-days. Improved access to Health and Community Care (HACC)-funded services can prevent some hospital admissions altogether, and can reduce average length of stay for those admitted. HACC is permitted to do the former, but not the latter! Oddly enough, both the Commonwealth and States gain financial relief through any reduction in hospital bed days, but the urge not to be beaten in the cost shifting game seems to defeat even financial self interest.

We have an incoherent hierarchy and minutely differentiated horizontally neighbouring service elements. For example, within the wider health and welfare system, primary care is not just the GP and the community health centre. It includes the HACC domiciliary services, home nursing, local counselling, support and relief agencies, respite facilities for relief of carers, accommodation under the Supported Accommodation and Assistance Program (SAAP), and even the private unsubsidised multiple-occupancy residential and boarding-house sector. Where these don't work, social conditions suffer. This has its most costly effects where it does the most damage - at the level of the most dependent and least self-reliant users of the service system. The big losers are the frail aged, the long term injured, people with chronic physical and psychiatric conditions, intellectually disabled people, substance abusers and so on, as well as the taxpayer who supports them all.

When local primary care arrangements fail these people, unnecessary demands are then placed on the much more expensive and often inappropriate, secondary (referral) elements of the systems: hospitals, nursing homes, hostels, and supported accommodation. These are often called upon for no other reason than that the narrow, over-specified local services cannot legally be packaged around the (often quite modest) needs of otherwise self-sufficient people.

Australia appears to have an unusually high rate of per capita admissions to hospital care relative to other OECD countries. One might speculate that it is the shambles of our primary-care system that forces many people into unnecessary hospital admission. The improved organisation of primary care is an absolute precondition to further evolution of the total Australian health, welfare and aged-care system. It can be done only at the local level, from pooled funds, but based on 'higher level' rules of eligibility and entitlement.

The primary-care system we have created contains abundant resources, and contains fragmentary elements of most of the services that would be in demand. They also exhibit absolute unmanageability, designed by a random walk, and operated by a command system straight out of Soviet orthodoxy.

\section{Structural Reform in Health}

Structural reform calls for three sets of measures. The first is to separate the catastrophic event and life-and-death elements of service demand from those consumption elements where market instruments can be allowed to mediate demand and supply. 
The second is to remove the 'imperfect information' road block which stands in the way of reasonable consumer choice. An 'agency' or case-management system can serve the informational needs of the market-based services as well as providing an organisational framework to service victims of catastrophic life events.

Third, the technical issues of output measurement, pricing, insurance, copayments and subsidisation must be addressed to recreate a transactional system in which contracts between governments and providers, or consumers and providers, can be made and enforced.

\section{Catastrophic Event Risk}

I know of no one in Australian public life who would argue (at least in public) that people suffering serious illness or injury, or a chronic disabling condition should be left to die in a gutter or subsist in poverty and filth. As a nation, we already make a big, if disorganised, effort to ensure that they don't.

The combined effect of our egg-crate style financing system and our weak primary care system is to guarantee great inconsistency in the level of care and support between different people in equally catastrophic circumstances. Some people eligible for intellectual disability services collect their pension and/or benefit and also get $\$ 50,000$ to $\$ 100,000$ of direct services per year each.

Some people in equally dire circumstances get no direct services at all and have their pension or benefits income ripped off by unscrupulous providers of last-gasp accommodation. Some get methadone treatment and tender loving care in therapeutic communities. Others do burgs, turn tricks and sleep rough to support their habit.

Our support systems for the most dependent are a lottery. They will remain so until we separate administration from the financing of care. There is already enough being spent to provide a decent basic standard if it is properly organised, and if it is regulated to proper service objectives rather than primarily with an eye to system maintenance.

At least half of the public direct service dollars in the health and welfare pot (exclusive of income security payments and private outlays) are spent on a small number of heavily supported people with chronic-acute conditions who are receiving a complex range of services. We might call them the victims of catastrophic events. They account for 5-10 per cent of the population. Most of the people concerned are old: some are physically and intellectually disabled; some have long term mental illnesses, drug and alcohol dependence, or are otherwise seriously ill. Most are supported by social security pensions and benefits, have next to no private resources, and make some, often quite some, demands on direct services in addition to their income security entitlements.

These people, together with the small number of privately insured or compensable people who are receiving intensive services at any particular time, can be 'insured' only through the public purse. These are the people for whom 'value of human life' rather than economic principles apply. Governments almost wholly support them now: at great cost, haphazardly and often poorly. They can be re- 
garded as claimants on reinsurance, toward which the whole tax system subscribes. Government should fix a pooled global budget to support their service needs and make it available through authorised agents of the beneficiaries.

Catastrophic event risk, including the risk of a life of chronic dependency, can only be insured through the tax system, with the whole population sharing the cost and obtaining the cover. In principle that situation prevails now: government steps in when all else fails. But it's not done very well because of the unevenness of categorical funding and service provisions and the fragmentation of primary care services. Our primary care system, in effect, forces the least resourceful people to be the biggest risk-takers.

The situation of 'catastrophic event' victims must be dealt with from both the service (supply) angle, and the financing angle. Australian experiments in the accident compensation field and American experience with managed care suggests that individual case management for victims of catastrophic event risk can control costs, radically improve quality of care, and remove most of the Kafkaesque nuances of life in the clutches of the system.

\section{An Agency Market}

In spite of mind-blowing institutional complexity, and an extraordinary degree of product differentiation, the international travel market is characterised by something approaching perfect information and perfect competition. Information is placed in the hands of even the least informed consumer by the travel agent. It rests on a handful of (competing and privately owned) booking systems. Those massive information systems allow modern travel arrangements to work. To the consumer they are invisible and travel looks like the simplest, purest, competitive market. Yet the degree of product differentiation and organisational complexity of the industry greatly exceeds even that of our gratuitously complicated health and welfare system.

An information base comparable to the international travel and accommodation booking systems would be required to make our health and welfare service work. Parts of this already exist in the medical, pharmaceutical and hospital service systems. There are no practical reasons why the health and welfare systems cannot be as well serviced with consumer information as the travel industry, and no reason why they cannot be as consumer responsive. The people working in health and welfare are at least as bright, the scale of the business is of similar order, and the stakes are much higher. There is, however, a threshold question to be faced: that of the privacy issues inherent in data matching. Data matching is inescapable if we want a better health system.

To 'perfect' the information available to the ordinary consumer, and to provide managed care for the highly dependent, we would also need to recognise an 'agency' function and be prepared to pay for it. Models exist in the GP Budget Holders in the new British system, the Health Maintenance Organisations and managed-care providers in the United States, and in elements of Australia's aged care, statutory welfare, and intellectual disability service systems that provide case management. 
Agency arrangements are vital for managing the care of victims of catastrophic events. The other half of health and welfare direct service spending is mostly incurred on a 'walk in walk out' basis by the other 90-95 per cent of the population. It might involve a visit to the GP, some tests, perhaps referral and specialist treatment in or out of hospital, and then it is over. For the 90 plus per cent of the population using services this way, no universal case management beyond the 'provider-to-provider' referral system is warranted.

However, if an otherwise healthy person has an episode calling for complex choices, such as a surgical procedure, then an agent may be useful. The agent may be a referring GP or some other. The agent should have screen-based and instantaneous access to a list of hospital/surgeon combinations operating within the preferred locality, and available at the preferred times. Unlike the GP in present conditions, an effective agent should also be able to advise, in respect of the possible providers: length of experience; number of procedure of the specific type performed in each recent year; statistical outcome indicators for cases treated by alternative providers; comparisons of the above with professional norms; and charges faced by consumer after insurance and any fee relief. That is where formal information systems come in.

There is no reason why 'agency' services could not be completely market-based, come from a variety of fields and offer a wide range of alternative contracts. Obvious providers could include GPs, community health centres, local government welfare departments, non-government not-for-profit agencies, and even commercial profit-seeking businesses.

\section{Case Payments and Output as the Organising Principle}

Any market-based system requires unique descriptors of the goods or services traded; otherwise there is no contract. Case-payment systems call for cases to be well defined. Such descriptors already exist for medical services, pharmaceuticals, and some allied health services. Victoria now uses diagnosis-related groups (DRGs) for reimbursement of public hospitals. There are, however, many remaining elements of the health and welfare system where useable basic descriptions do not exist. There are gaps to be filled, but in Victoria, at least, these gaps are being filled quickly.

Apart from meeting the technical requirement of market allocation, a case payment system is also a powerful antidote to bureaucratic games and consequential overhead costs. In Victoria until 30 June 1993 we at the Department of Health and Community Services sure regulated hospitals. But then we also met the cost of their inputs, regardless of how little output they produced, so we paid for our fun. We ran the public hospitals' industrial relations for them. We rained circulars down on them like confetti. We told them who should do their laundry, which ambulances to use, and when they could replace their bedpans. And we kept the hospitals guessing about how much money they would get from year to year. But the hospitals knew that no matter how hopeless they were, they wouldn't be forced to leave the game. On the other hand to keep them respectful, we made sure that 
no matter how good they were, they would not be allowed to get far ahead of the pack. This kind of thing also applied in children's welfare, intellectual disability services and so on. It was made possible by cost reimbursement funding and nonmarket (i.e. administrative) allocation of product to consumers.

Under the hospital-case payments and the other output-based payment systems introduced in Victoria in 1993, hospitals and most other funded bodies now get paid for what they do: no more and no less. The price is realistic: the DRG price we paid all public hospitals in 1993/94 was enough to fully cover the costs of the best hospitals as they stood in 1992/93.

There is no originality, and definitely no particular genius about output based payment systems: you buy your groceries that way and it seems to work. Nevertheless, it is a revolutionary measure in government, and produces immediate and dramatic gains in efficiency if properly used.

\section{Transitional Funding Pool}

It is much easier to corrupt a market than to uncorrupt it. We can uncorrupt the national health and welfare market (carefully) by using pooled funding to preserve fiscal neutrality while reassigning administrative responsibilities and building a system of consumer entitlements, insurance, agency and co-payments. Funds pooling, properly used, means death to the sport of cost shifting.

It is possible to identify fairly precisely just who, in any past year, was spending what. Any move to uncorrupt our health and welfare markets could easily start with a funds pooling treaty, allowing sources of funds to be detached from regulation of services during a finite period of structural adjustment.

Victoria is showing right now that it is perfectly simple to detach cost reimbursement grants from privileged providers, and then to use the funds to pay for provision of specific services at prospectively determined prices. It is also easy to arrange a greater or lesser degree of contestability between providers.

It is also possible to grandparent in case-payment arrangements: in 1993/94 in Victoria we paid each non-benchmark hospital a 'compensation grant' equivalent to about 40 per cent of the fat that was in the respective cost structure of that hospital last year, giving them a little longer to adjust to the chill winds of competition.

\section{Reassigning Roles}

There is little congruence at present between the hierarchy of government and the hierarchy of health and welfare functions, and there is much to be gained from reordering roles.

There are usually large economies of scale available from centralised payment systems. This should be the role of the Commonwealth. On the other hand, inspection, supervision, licensing, and so on, is often best done fairly locally, at State or regional level.

My Department runs the case payment system for Victoria's 157 hospitals with around 100 officials and a little outside computing and auditing help. When the 
system settles down it will be less than 100. Once public hospitals across Australia are on a case-payment system the Commonwealth could win benefits of scale by paying all the nation's hospitals on an identical basis. The Health Insurance Commission could post the cheques. It already pays private medical practitioners and could at little cost make case payments to community health centres and public hospital outpatient departments.

Where does that leave the States? My Department directly funds several thousand providers of what could be broadly described as primary care (walk-in walk out) services or secondary care (low technology referral based) services. It is those we are now progressively moving over to output based payment at benchmark prices. Most of these providers are fairly specialised health and welfare agencies. Generally they run good to excellent supported accommodation, therapy, counselling, community health and other services for those lucky enough to find a place in them. Most are not well integrated with other local services. This is largely because their balkanised, programmatic and overspecialised funding base makes integration difficult and sometimes even illegal. Just think about SAAP and the 'community' facilities earmarked respectively for psychiatric, intellectual disability, drug and alcohol, or transitional criminal justice clients. You can't mix them without shrill charges of cost shifting from Canberra. There is a major 'State level' job to be done in completely reorganising 'small end' primary care systems.

Beyond directly government-funded services there are private facilities that accommodate, at various levels of dignity, comfort and support, aged, infirm, disabled, psychiatrically ill, itinerant and all manner of other people. The bulk of the occupants are supported by Commonwealth pensions or benefits. The lucky ones also receive some direct health, welfare and recreational services.

Private accommodation in Victoria includes Special Residential Services (SRS) and boarding houses. The best of the SRS make an international hotel look ordinary. Other SRS and some boarding houses are reasonably clean, comfortable, and well run. Others are disgusting. We and/or the Commonwealth, and/or local government, and/or in some cases, no one, registers or licenses them and, for the most part, it is done badly.

The cost of doing a lot better would generally be pretty modest, but there does need to be an effective administrative oversight authority and a tie in with local services. State/local government agencies are probably best equipped to do that.

Within a single grotty boarding house you might find ten residents: three with a history of psychiatric illness, two who are registered as intellectually disabled, a couple of people with substance-abuse histories, one recently out of prison, and two who are down on their luck. All have pretty similar needs. The Salvation Army and a handful of other non-profit bodies do provide services to people just because they are in need, regardless of their 'primary diagnosis'. Otherwise, the only way of servicing those ten people is through a minimum of five separate, vertically integrated programs which have very weak horizontal interconnections locally. Yet all that is really needed is someone to keep an eye on things, to check on personal cash management, hygiene and medication, sort out squabbles, identify personal crises 
and acute health events, and so. It doesn't need to be expensive, but we usually do it either at exorbitant cost or (more often) not at all.

The British National Health Service worked in spite of its resemblance to the economy of the USSR because it was based on effective primary-care arrangements. GPs were gatekeepers for health services, and most local authorities were reasonably capable providers of basic welfare and support services. That was its strength. Its weakness was the characteristic weakness of a large bureaucracy: it lacked the capacity for adaptation and change. It tolerated high cost providers long after the market would have buried them. Until we introduced case mix, we in Victoria did the same. The rest of Australia is still doing it.

\section{Rebuilding the Funding Base}

The hot topic right now is private health insurance, which is collapsing before our very eyes. Its salience arises from its political symbolism, not from its significance in overall health and welfare financing: it supplies only the marginal dollar. Private health insurance is an artefact of a regulatory divide between public and private hospitals. It creates two 'insurance' markets, and a dual health services system.

The one-to-one connection between hospital funding source and hospital service provider creates a bizarre distortion of the market for services. It is only in part public regulation which enforces the division. Benevolent societies were the ancestors of contemporary private health insurance. Their membership bases were typically based on affiliation rather than risk status, so they could be said to be 'community rated'. Modern markets for risk know no sectarian affiliation. Insurance markets are structured in horizontal layers of risk rather than in vertical slices of affiliation. Our health insurance system is an oddity. The attempt to enforce community rating on all private funds is, in effect, an attempt to reinforce and perpetuate the anachronistic 'vertical' or sectarian organisation of health insurance, and to perpetuate a dual health system.

Given Medicare bulk billing and free public hospitals, the fact is that basic medical and hospital services are guaranteed de jure, though, of course, not de facto, to everyone. Hospital waiting lists and some restrictions on choice impose a small gap between the de jure and de facto situation. Private insurance can offer better patient choice/control, better hospital accommodation, and a ticket to jump queues, but the benefits are at the margin whereas the insurance offer is priced for the total service.

Private insurers have been forced by regulation to price the product not to cover the quite marginal advantages it confers, but to cover the whole 'community rated' cost of care. This includes the deepest layers of catastrophic risk. No wonder the customers are voting with their feet. Private insurance is grossly overpriced for the limited de facto advantages it confers.

The effort to force community rating on private insurers is self-defeating because it kills the private insurance market. It is a ludicrous misapplication of regulatory effort. This is apparent to everyone, and yet it continues. How can this be? It stems from a confusion of means and ends in the minds of (federal) legislators. In 
theory, they want to prevent cream-skimming by the private funds; but in practice their efforts merely load up the public system - for which, however, they are unwilling to pay.

\section{Reconstructing Co-payments}

If we can create adequate local support systems to deal with chronic dependency and catastrophic illness, we can then treat the remainder of health and welfare services as economic phenomena. This does not mean emulation of the American health care system. It means using a mix of income redistribution, public regulation, public funding, private insurance, self insurance, and 'public health' (i.e. environmental) measures to produce the level of service and the distribution of costs and benefits we choose. It removes the regulatory junk that stands in the way of an efficient and responsive health system.

Consumer sovereignty supported by an agency system would ensure that providers are competition exposed. That happens to be perfectly consistent with the use of managed care for the five to ten per cent of population who are 100 per cent financed from the tax base. They will be comprehensively 'case managed' by an agent acting on their behalf or at their instruction. Agency services will also be used by the wider population on an episodic, as needed, basis.

In almost every existing element of the 'non-catastrophic' service system there are already some elements of co-payment, of fee relief, and of status-based entitlements to free service. These devices are inconsistently, and even capriciously applied. The range of service choices available to the consumers is generally much narrower than a competitive system would produce. We in Victoria are actively sorting out those distortions, but we are seriously constrained by the conditions of funding established by the Commonwealth.

Competitive neutrality between providers of an identical service is a sine qua non of an efficient market. The contribution made respectively by the insurer (say, the Health Insurance Commission), 'the Treasury' (as the source of income-related fee relief) and the user should be independent of whether the provider is a GP, a community health centre, a public hospital outpatient department or any other recognised provider.

\section{Concluding Remarks}

I do not pretend that microeconomic reform of health and welfare will be without distinctive difficulties. But there is enough at stake to justify the effort. It is possible to proceed piecemeal, so long as there is a general agreement about the direction to take. The essentials are:

- separate out victims of catastrophic risk and case manage their care;

- build upon existing large-scale information systems so that they eventually coalesce; 
- complete the system of product or unit output descriptors;

- ensure that all payments, even by governments, are for outputs and not inputs;

- gradually move government funded providers over to fee charging status;

- abandon community rating obligations in private insurance; and

- allow complete freedom in the nature of the insurance contract, subject to rigorous prudential requirements.

All that is needed to make a start is political leadership. The technical requirements are routine.

This article is an edited version of a paper originally published in Investing in Health Care - A Challenging Future, papers presented at an Office of EPAC seminar held in Canberra on 15 October 1993 (EPAC Background Paper No. 34). The views expressed are those of the author and should not be construed. otherwise. 